\title{
How would peak rainfall intensity affect runoff predictions using conceptual water balance models?
}

\author{
B. Yu \\ School of Engineering, Griffith University, Nathan 4111, Australia \\ Correspondence to: B. Yu (b.yu@griffith.edu.au)
}

Received: 11 March 2015 - Accepted: 11 March 2015 - Published: 12 June 2015

\begin{abstract}
Most hydrological models use continuous daily precipitation and potential evapotranspiration for streamflow estimation. With the projected increase in mean surface temperature, hydrological processes are set to intensify irrespective of the underlying changes to the mean precipitation. The effect of an increase in rainfall intensity on the long-term water balance is, however, not adequately accounted for in the commonly used hydrological models. This study follows from a previous comparative analysis of a non-stationary daily series of stream flow of a forested watershed (River Rimbaud) in the French Alps (area $\left.=1.478 \mathrm{~km}^{2}\right)(1966-$ 2006). Non-stationarity in the recorded stream flow occurred as a result of a severe wild fire in 1990. Two daily models (AWBM and SimHyd) were initially calibrated for each of three distinct phases in relation to the well documented land disturbance. At the daily and monthly time scales, both models performed satisfactorily with the Nash-Sutcliffe coefficient of efficiency (NSE) varying from 0.77 to 0.92 . When aggregated to the annual time scale, both models underestimated the flow by about $22 \%$ with a reduced NSE at about 0.71 . Exploratory data analysis was undertaken to relate daily peak hourly rainfall intensity to the discrepancy between the observed and modelled daily runoff amount. Preliminary results show that the effect of peak hourly rainfall intensity on runoff prediction is insignificant, and model performance is unlikely to improve when peak daily precipitation is included. Trend analysis indicated that the large decrease of precipitation when daily precipitation amount exceeded $10-20 \mathrm{~mm}$ may have contributed greatly to the decrease in stream flow of this forested watershed.
\end{abstract}

\section{Introduction}

Most concceptual hydrological models such as AWBM and SimHyd for streamflow estimation require, as input, continuous daily precipitation and potential evapotranspiration. With the projected increase in the mean surface temperature as a result of elevated level of $\mathrm{CO}_{2}$ concentration in the atmosphere, hydrological processes, precipitation especially, are set to intensify irrespective of the underlying changes to the mean precipitation. The effect of an increase in rainfall intensity at the sub-daily time scale on the long-term water balance is, however, not adequately accounted for in the commonly used hydrological models. As part of a workshop on modelling non-stationary time-series of streamflow, attempt was made to compare the performance of AWBM and SimHyd when calibrated using daily data for two forested watersheds in France and the USA (Yu and Zhu, 2014). For the Rimbaud watershed, the non-stationarity was noted be- cause of a marked decrease in stream flow in recent decade, and of a severe wild fire in 1990. The wild fire in August 1990 resulted in extensive damage to vegetation for up $80 \%$ of the watershed. The wild fire had also affected the watershed hydrology at the time with a noticeable increase in streamflow (Cosandey et al., 2005). AWBM and SimHyd were found to be adequate in decribing the hydrology of the Rimbaud watershed using the workshop protocal, and the effect of the wild fire in the watershed on stream flow was found to be secondary relative to the declining precipitation and streamflow during the study period from 1968 to 2006 (Yu and Zhu, 2014).

It is widely known that all other factors being the same, rainfall events high in its intensity and low in its duration would result in a greater amount of runoff. Rainfall intensity, however, is rarely explicitly included as part of input data requirements for conceptual hydrologic models. In fact, failure 
to include the effect of rainfall intensity has been cited as one of the serious limitations of the SCS-CN (Soil Conservation Service-Curve Number) method for storm runoff predictin (Ponce and Hawkins, 1996). The effect of rainfall intensity is not explicitly taken into consideration in hydrologic models, possibly because (1) rainfall intensity is indeed unimportant due to, for instance, saturation excess as the sole mechanism for runoff generation; (2) information on rainfall intensity is already embedded in daily precipitation because rainfall intensity and rainfall amount are positively correlated; (3) data on rainfall intensity were not readily available, hydrologic models that require rainfall intensity as input would unlikely be popular due to data limitations. It is therefore interesting to find out whether inclusion of rainfall intensity as an input variable in hydrologic models would improve model performance, in particular for this non-stationary time-series of decreasing runoff from this forested watershed.

Of the 14 watersheds for the workshop, sub-daily precipiation data at hourly intervals were available for the Rimbaud watershed for the study period from 1966 to 2006. The objectives of this preliminary study were (1) to assess model performance for distinct phases of the watershed: (a) pre-fire, (b) fire-affected; (c) post-fire; (2) to relate model residuals to peak rainfall intensity on a daily basis; (3) to relate the decline in stream flow to changes in precipitation, potential evapotranspiration and rainfall intensities.

\section{Data and method}

Daily precipitation, temperature, potential evapotranspiration, and streamflow data were assembled by IRSTEA (http://non-stationarities.irstea.fr/data-2/data/) for 14 catchments around the world (Thirel et al., 2014). For one of the smallest watersheds, i.e. the River Rimbaud in France $\left(\right.$ Area $\left.=1.478 \mathrm{~km}^{2} ; 43.21^{\circ} \mathrm{N}, 6.31^{\circ} \mathrm{E}\right)$, hourly precipitation and streamflow data were also made available. Daily and hourly precipitation and streamflow data for this small forested watershed were used for this study. The River Rimbaud watershed is located in the Mediterranean part of southern France, and experiences a Mediterranean climate with the 4 wettest months from October to January. For the 4 months from May to September, the potential evapotranspiration exceeds precitation for the watershed (Fig. 1). July is the driest month of the year in terms of precipitation and streamflow. For this resaon, a water year is defined as from August to July for this watershed. Mean daily values were computed for each month using all the available data, and these mean daily values were multiplied by the number of days in each month to derive the mean monthly values (Fig. 1). The mean annual precipiation and potential evapotranspiration were 1059 and $999 \mathrm{~mm}$, respectively. The mean annual streamflow was $653 \mathrm{~mm}$, indicating a gross runoff coefficient of $62 \%$ for the River Rimbaud watershed for the study period (1966-2006). Thirel et al. (2014) presents location maps, and additional

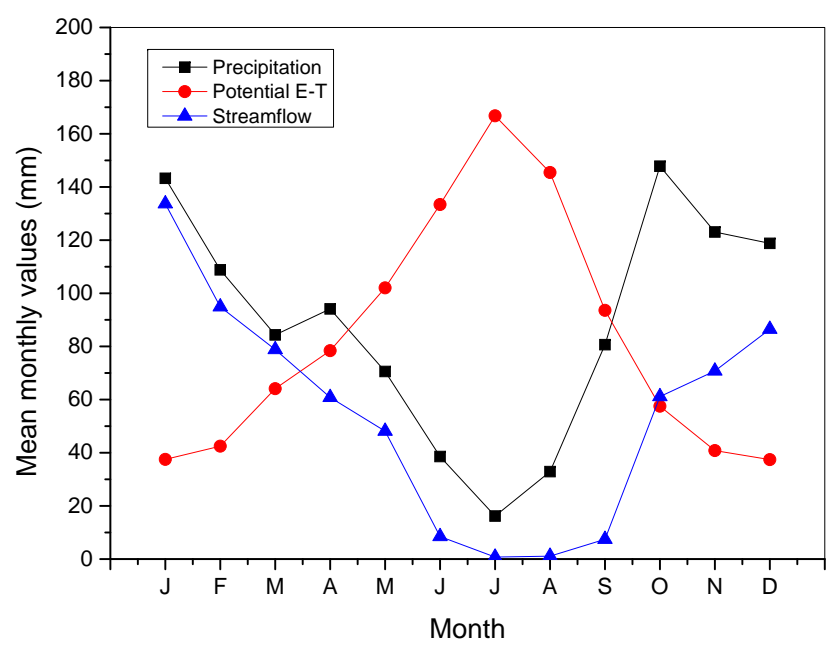

Figure 1. Mean monthly precipitation, potential evapotranspiration, and stream flow for the Rimbaud watershed in southern France.

descriptions of the climatic and hydrological characteristics of these watersheds.

Whilest data were made available for the period from 1966-2006, on close inspection, no streamflow data were available until 23 August 1967 . The study period was thus reduced to 39 years from January 1968 to December 2006. For the 39 years, there were 151 out of 14245 days (or $1.1 \%$ ) with mising precipiation data and 324 days of missing streamflow data $(2.3 \%)$. Missing precipiation data were backfilled using a stochastic weather generator CLIGEN as daily time series of weather variables without missing values are needed for continuous hydrological simulations. CLIGEN parameter values were computed using all the available daily data and the method described in detail in Yu (2005). Wet days were defined as those when precipitation $\geq 0.1 \mathrm{~mm}$. A 100-year daily climate sesquence (1961-2060) were generated with an initial seed of 123 so that the generated time series can be reproduced if needed. A complete daily precipitation time series was created by combining the observed daily precipitation and simulated daily precitation amount on only those days when observations were not available (151 out of 14245 days). Streamflow data for days when precipiation data were missing were not used for model calibration and validation, even if they were available. Temperature and potential evapotranspiration data were complete for the period (1966-2006), back-filling was therefore not needed for the two variables.

The native vegetation is Maquis shrubland. In $\mathrm{Au}-$ gust 1990, a severe forest fire destroyed more than $80 \%$ of the forest cover of the watershed. An increase in peak discharge was noted, especially during heavy rainfall events following the fire (Cosandey et al., 2005). The shrub cover returned quickly on the burned surfaces: $15 \%$ in August 1991, $30-35 \%$ in August 1992, and 45-50\% in August 1993 (Cosandey et al., 2005), and Cosandey et al. (2005) conclude 
that the effect of the wild fire is not detectable for the watershed after four years, and there is no permanent change to soil structure in the watershed. Because of the changes to vegetation cover, three distinct phases were considered for model calibration and comparison purposes:

- Phase 1: pre-fire, 20 years from August 1970 to July 1990,

- Stage 2: fire-affected, 4 years from August 1990 to July 1994,

- Stage 3: post-fire, 14 years from August 1994 to July 2006.

Both AWBM and SimHyd are developed in Australia, and both are conceptual and lumped hydrologic models to simulate daily flows (Boughton, 1995, 2004; Chiew et al., 2002). Input requirements are identical, including daily precipitation and daily potential evapotranspiration. The latter was often substituted with the mean daily evapotranspiration for the month, for the model output is not particularly sensitive to the potential evapotranspiration. The two models have been included in a software package known as Rainfall-Runoff Library (RRL) to share a common interface for model calibration and simulation, parameter estimation, and visualisation (Perraud et al., 2003; Podger, 2003; Kim et al., 2005) as they are sufficiently similar in data requirement and modelling capabilities.

AWBM has 3 unconnected surface stores with varying capacities (C1, C2, C3) and partial areas, and a sub-surface store with unlimited capacity (Boughton, 1995, 2004). As the sum of the 3 partial areas equals unity, only two partial areas (A1, A2) are "free", adjustable parameters. When rainfall excess is produced from one or several of the surface stores, the excess is partitioned into two components, one recharging the surface runoff store and the other recharging the store for the sub-surface flow. This is achieved via a single parameter known as the baseflow index (BFI). Daily runoff is computed as the sum of surface and sub-surface flows using a linear recession relationship. In total, AWBM has up to 8 adjustable parameters. Five of the 8 parameters determine the amount of stream flow and the remaining 3 only affect how stream flow is distributed in time.

SimHyd is actually a simplified version of another daily rainfall-runoff model developed in the 1970s (Porter and McMahon, 1975). Unlike AWBM with unconnected surface stores, SimHyd conceptualises the runoff from 4 different sources: direct runoff from impervious areas, runoff due to infiltration excess, interflow, and baseflow from a groundwater store. Apart from the infiltration capacity which is modelled as a non-linear function of the soil moisture, all other relationships are linear and constrained by store capacities. Chiew et al. (2002), RRL user guide (Podger, 2003), and Zhang and Chiew (2009) provide additional technical details. For the Rimbaud watershed, there are effectively 7 calibra- tion parameters as the impervious fraction was assumed to be zero for forested watersheds.

To calibrate AWBM and SimHyd for the Rimbaud watershed, genetic algorithm was used to estimate model parameters. The sum of the squared difference (SSE) between observed and modelled daily flows was used as the objective function to be minimized. For each of the three distinct phases, a period of at least 35 months was used as the warmup period for calibration purposes. For AWBM, five parameters have a logical upper limit of unity. For the three remaining parameters, upper limits were specified as default in RRL. For SimHyd, three parameters have a logical upper limit of unity, upper limits for the remaining 4 were specified as default in RRL. Three different sets of initial parameter values, at 25, 50 and $75 \%$ of these upper limits for these parameters were used for parameter calibration for AWBM and SimHyd. Optimal parameter values were obtained in terms of the minmum SSE values using daily flows for each of the three phases.

Nash-Sutcliffe coefficient of efficiency (NSE) was used in this study to asssess model performance (Nash and Sutcliffe, 1970). Linear regression was used extensively for exploratory data anlysis of the relationship between rainfall intensity and model performance, and of the time series of precipitation, potential evapotranspiration, and rainfall intensities.

\section{Results}

\subsection{Model calibration}

Tables 1 and 2 present calibration results for AWBM and SimHyd, respectively, for each of the three distinct phases with respect to watershed conditions. The mean annual precipitation was the highest during the pre-fire phase $\left(1138 \mathrm{~mm} \mathrm{yr}^{-1}\right)$, and the lowest during the fire-affected phase $\left(957 \mathrm{~mm} \mathrm{yr}^{-1}\right)$. In comparison, the potential evapotranspiration was on the increase with the highest during the post-fire phase $\left(1031 \mathrm{~mm} \mathrm{yr}^{-1}\right)$. Volumetric runoff coefficient, i.e. the ratio of stream flow over precipitation, decreased from 69 to $59 \%$ from Phase 1 to Phase 3. The performance of AWBM and SimHyd was similar in terms of the Nash-Sutcliffe coefficient of efficiency. NSE was at least 0.83 at the daily scale for AWBM and at least 0.84 for SimHyd. SimHyd was marginally better than AWBM for all three phases (Tables 1 and 2). Although monthly values were not used for optimization purposes, the Nash-Sutcliffe coefficient of efficiency was used to indicate model performance at the monthly time scale. Results presented in Table 2 show that SimHyd is slightly but consistently better than AWBM using monthly values. These observations are broadly consistently with what was noted in Yu and Zhu (2014).

Figure 2 shows the annual time series of observed and modelled stream flow using calibrated AWBM and SimHyd. Calibrated parameter values were used for each of the three 
Table 1. Precipitation, potential evapotranspiration, stream flow, and calibrated parameter values using AWBM for each of the three phases for the Rimbaud watershed in France.

\begin{tabular}{lrrr}
\hline & Phase I & Phase II & Phase III \\
\hline Period & Aug 1970-Jul 1990 & Aug 1990-Jul 1994 & Aug 1994-Jul 2006 \\
\hline Precipitation $\left(\mathrm{mm} \mathrm{yr}^{-1}\right)$ & 1138 & 957 & 996 \\
Potential $E-T\left(\mathrm{~mm} \mathrm{yr}^{-1}\right)$ & 968 & 1017 & 1031 \\
Streamflow (mm yr & - $)$ & 612 & 585 \\
Partial area 1 & 784 & 0.529 & 0.486 \\
Partial area 2 & 0.275 & 0.124 & 0.514 \\
Store capacity 1 (mm) & 0.105 & 35.5 & 47.8 \\
Store capacity 2 (mm) & 26.3 & 104.3 & 182.0 \\
Store capacity 3 (mm) & 105.9 & 125.5 & 500.0 \\
Weighted store capacity (mm) & 138.0 & 75.3 & 116.8 \\
Baseflow index & 103.9 & 0.451 & 0.769 \\
Baseflow recession coefficient & 0.349 & 0.706 & 0.561 \\
Surface flow recession coefficient & 0.541 & 0.341 & 0.455 \\
NSE (Daily) & 0.635 & 0.891 & 0.917 \\
NSE (Monthly) & 0.832 & 0.770 & 0.885 \\
\hline
\end{tabular}

Table 2. Calibrated parameter values using SimHyd for each of the three phases for the Rimbaud watershed in France.

\begin{tabular}{lrrr}
\hline & Phase I & Phase II & Phase III \\
\hline Interception store capacity (mm) & 3.08 & 2.31 & 2.31 \\
Infiltration coefficient $\left(\mathrm{mm} \mathrm{h}^{-1}\right)$ & 251 & 309 & 364 \\
Infiltration shape (-) & 0.941 & 1.80 & 0.392 \\
Interflow (-) & 0.00784 & 0.0863 & 0.0353 \\
Recharge coefficient (-) & 0.404 & 0.651 & 0.475 \\
Baseflow coefficient & 0.396 & 0.373 & 0.435 \\
Moisture capacity (mm) & 118 & 63.6 & 140 \\
NSE (Daily) & 0.840 & 0.897 & 0.922 \\
NSE (Monthly) & 0.893 & 0.810 & 0.901 \\
\hline
\end{tabular}

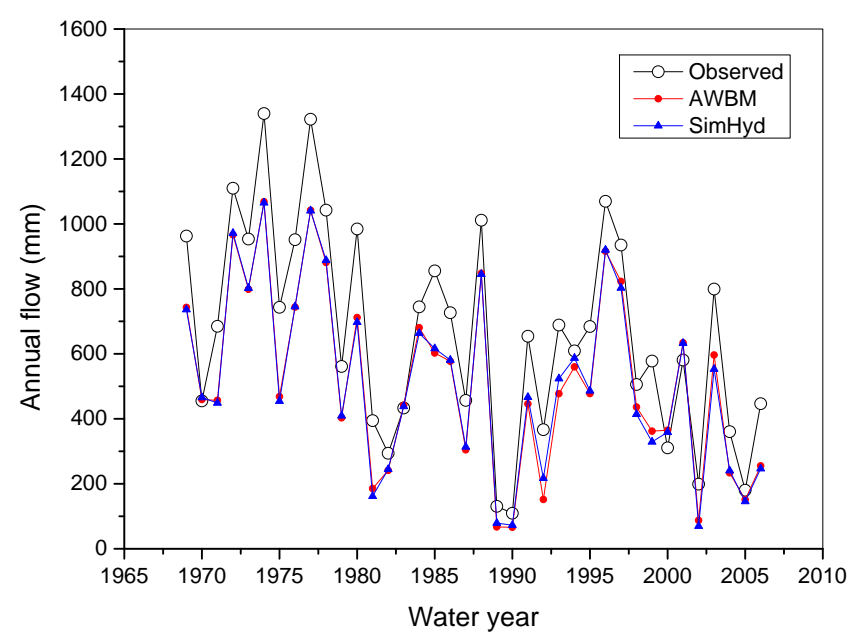

Figure 2. Observed and modelled annual flows using two conceptual hydrological models for the Rimbaud watershed. separate phases. Annual flows from the three distinct phases were assembled to illustrate model performance when the flow was aggregated at the annual time scale. It is clear from Fig. 2 that the both models systematically underestimated the annual flows by about $22 \%$ on average, although they are able to reproduce year-to-year variations in stream flow for the watershed. The Nash-Sutcliffe coefficient of efficiency was 0.709 for annual flows using AWBM and 0.706 using SimHyd. These were much lower than the Nash-Sutcliffe coefficient of efficiency for daily and monthly flows (Tables 1 and 2). Modelled annual flows using AWBM and SimHyd are quite similar (Fig. 2) in terms of the bias and NSE values. It is also relevant to note that this is a costly exercise, given that it took three sets of parameter values to produce this single modelled annual series of stream flows for the watershed.

\subsection{Parameter values}

For this non-stationary time series of declining stream flow, two conceptual hydrologic models were calibrated and evaluated for three distinct phases aligned with well documented land disturbance as a result of a wild fire in 1990. This approach was different from the modelling protocol adopted for the workshop where 5 sub-periods of 7 years each were used for cross-validation purposes (Thirel et al., 2014). A comparison of parameter values calibrated for each of the three phases is useful in identifying the underlying non-stationary behaviour of stream flow for this watershed. For AWBM, Fig. 3 shows the relationship between the effective daily precipitation and runoff when the watershed is fully saturated and that when the watershed is at its maximum dryness. It is evident that the relationship is non-linear, and for a given amount of effective precipitation the runoff would be higher during Phase 2 in comparison with the other two phases. 


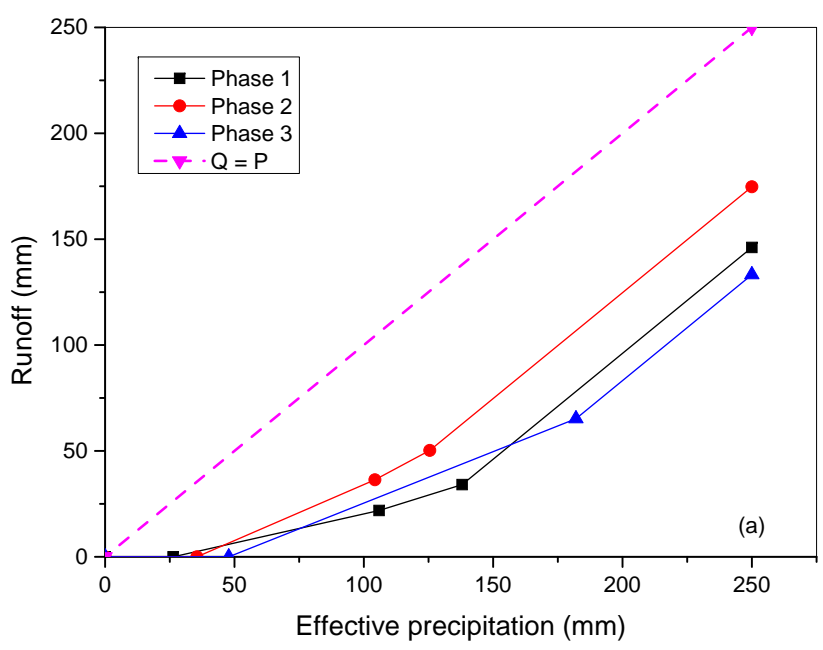

Figure 3. The effective precipitation-runoff relationship for the AWBM model (Phase 1: August 1970-July 1990; Phase 2: August 1990-July 1994; Phase 3: August 1994-July 2006).

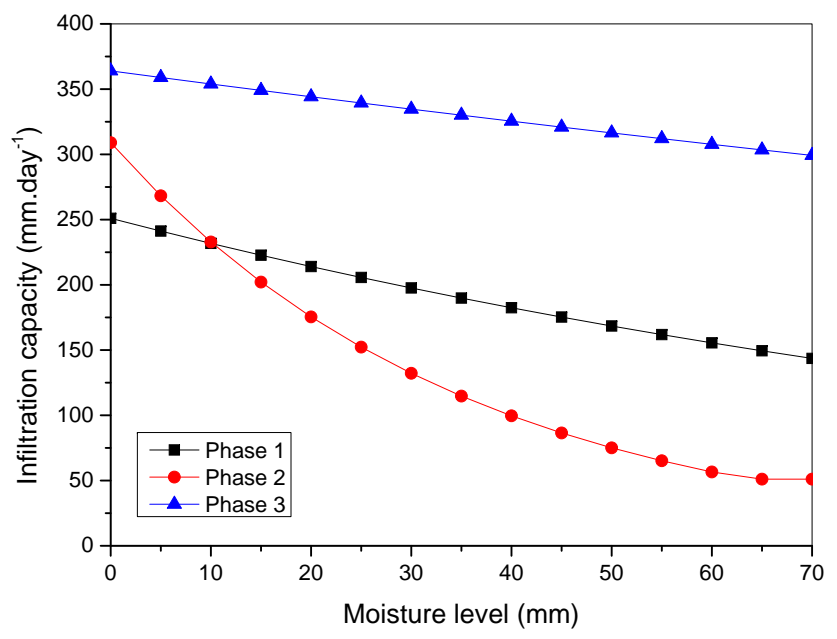

Figure 4. The infiltration capacity as a function of moisture content relationship for the SimHyd model (Phase 1: August 1970July 1990; Phase 2: August 1990-July 1994; Phase 3: August 1994July 2006).

This tends to support the observation that runoff was higher during the 3-4 years immediately following the wild fire. The weighted average store capacity for Phase $2(75.3 \mathrm{~mm})$ was noticeably less than that for Phase 1 and 3 (103.9 and $116.8 \mathrm{~mm}$, respectively, Table 1) suggesting around $30 \%$ reduction in store capacity for soil moisture following the wild fire. A slightly higher (12\%) store capacity for Phase 3 than for Phase 1 is likely a result of calibration using the decreased stream flow for Phase 3.

For SimHyd, a similar comparison was made of calibrated parameter values for different phases. Figure 4 shows the infiltration capacity as a function of the moisture content of the watershed using the calibrated parameter values from Ta-

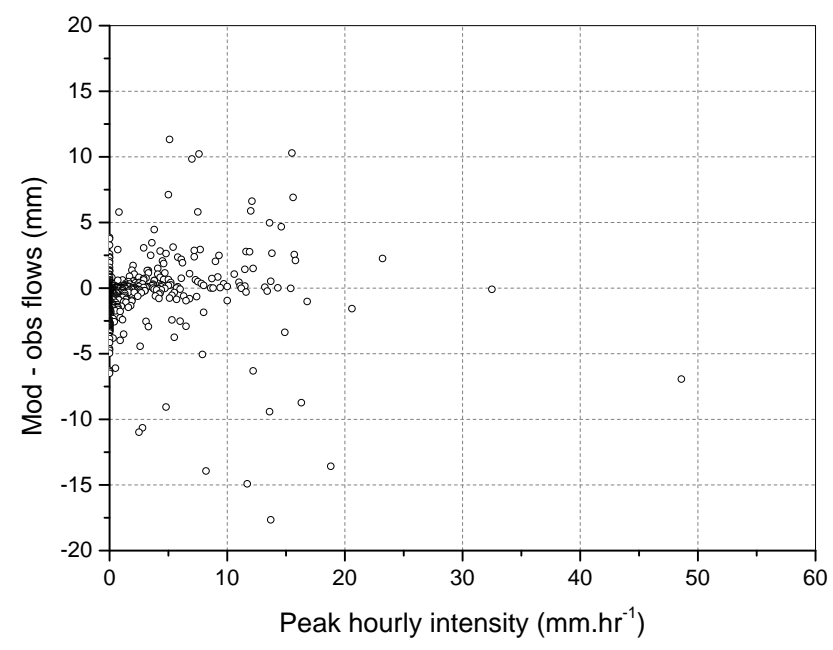

Figure 5. The relationship between model residuals (modelled and observed daily flows) and peak hourly rainfall intensity for Phase 2 (August 1990-July 1994) using SimHyd.

Table 3. The sign and strength of correlation $\left(r^{2}\right)$ between the peak hourly rainfall intensity $\left(\mathrm{mm} \mathrm{h}^{-1}\right)$ and the difference between modelled and observed daily flows ( $\mathrm{mm}$ ) for the Rimbaud watershed in France.

\begin{tabular}{lrrr}
\hline$r^{2}$ & Phase I & Phase II & Phase III \\
\hline AWBM & $(+),<0.001 \%$ & $(-),<0.1 \%$ & $(+),<1 \%$ \\
SimHyd & $(+),<1 \%$ & $(+),<0.1 \%$ & $(+),<0.001 \%$ \\
\hline
\end{tabular}

ble 2. It is clear from Fig. 4 that the infiltration capacity is consistently lower for Phase 2 than that for Phase 1 and 3. This is consistent with the implied precipitation-runoff relationship for AWBM and the observed increase in stream flow following the wild fire. The infiltration capacity for Phase 3 was much higher (364 $\mathrm{mm}$ for Phase 3 and $251 \mathrm{~mm}$ for Phase 1 , or a $45 \%$ increase, when the moisture level is $0 ; 316 \mathrm{~mm}$ for Phase 3 and $168 \mathrm{~mm}$ for Phase 1, or a $88 \%$ increase when the moisture level is $50 \mathrm{~mm}$; see also Fig. 4) than that for Phase 1 for SimHyd in comparison to AWBM. This marked reduction in the infiltration capacity is probably again the model's attempt to match the observed reduction runoff for Phase 3. In addition, it is worth noting, that the daily precipitation exceeding $50 \mathrm{~mm}$ a day occurred twice from 1966 to 2006, and none during Phase 2. This implies that there would be essentially no infiltration excess according to the calibrated parameter values for SimHyd.

\subsection{Effect of rainfall intensity}

As an exploratory data analysis, model residuals, i.e. the difference between modelled and observed daily flows are plotted against the peak hourly rainfall intensity for the day with Fig. 5 as an example for Phase 2 using SimHyd. The sign, 
Table 4. Analysis of precipitation trends for different intensity thresholds for the period from 1966 to 2006 for the Rimbaud watershed in France.

\begin{tabular}{lrrrr}
\hline $\begin{array}{l}\text { Threshold } \\
\left(\mathrm{mm} \mathrm{day}^{-1}\right)\end{array}$ & $\begin{array}{r}\text { Mean amount } \\
\left(\mathrm{mm} \mathrm{yr}^{-1}\right)\end{array}$ & $\begin{array}{r}\text { Mean number } \\
\text { of days }\end{array}$ & $\begin{array}{r}\text { Decrease in a decade } \\
\text { as \% of the mean }\end{array}$ & $p$ value \\
\hline$>0$ & 1047 & 114 & $-8.5 \%$ & 0.041 \\
$>2$ & 1018 & 56 & $-8.6 \%$ & 0.044 \\
$>5$ & 966.1 & 40 & $-9.0 \%$ & 0.042 \\
$>10$ & 875.3 & 28 & $-9.3 \%$ & 0.046 \\
$>20$ & 704.3 & 16 & $-9.9 \%$ & 0.066 \\
$>50$ & 333.1 & 4.5 & $-8.3 \%$ & 0.316 \\
\hline
\end{tabular}

positive or negative, the strength of correlation $\left(r^{2}\right)$ are presented in Table 3. It is quite clear from Table 3 that for both conceptual hydrological models, there is no significant correlation between peak hourly rainfall intensity and whether the daily flow was overestimated or underestimated. This was true when the watershed was well vegetated, and this was also true when the watershed was severely burnt during Phase 2. Based on the evidence presented, performance of these daily hydrological models is unlikely to improve when peak rainfall intensity is included as additional model input for this watershed.

For 38 water years from August 1968 to July 2006, annual stream flows decreased significantly ( $p$ value $=0.0027$ ). The rate of decrease was about $14 \mathrm{~mm}$ a year, or $21 \%$ of the mean every decade. For the same period, precipitation decreased significantly ( $p$ value $=0.0082$ ) by $11.5 \mathrm{~mm}$ a year or $-11 \%$ of the mean every decade. The potential evapotranspiration showed a significant ( $p$ value $=0.0033$ ) increase of $3.6 \mathrm{~mm}$ a year or $3.6 \%$ of the mean in a decade. Time series analysis of the annual series of the maximum hourly rainfall intensity showed that there was no significant change to peak rainfall intensity for the watershed ( $p$ value $=0.62$ ). For precipitation amount in excess of a specific threshold, Table 4 shows that annual precipitation when daily totals exceed $10-20 \mathrm{~mm}$, the increase over the period from 1966 to 2006 was the greatest in percentage terms. For this watershed, this is the only piece of evidence found so far to suggest that that precipitation during heavy rainfall events may have contributed most to the declining stream flow of the Rimbaud watershed.

\section{Conclusions}

As part of a continued effort to examine the non-stationary time series of declining stream flow of a small, well instrumented research watershed in southern France, the initial objective was to test whether additional information on subdaily rainfall intensity would improve the performance of hydrologic models. AWBM and SimHyd were used for each of three distinct phases: (a) pre-fire; (2) fire-affected; and (3) post-fire. Conclusions from this preliminary study can be summarised as follows:
1. The two conceptual hydrological models performed similarly and satisfactorily for this small watershed at both daily and monthly time scales.

2. Neither model is able to reproduce stream flows at the annual time scale. AWBM and SimHyd underestimated the mean annual flow by about $22 \%$ with a reduced Nash-Sutcliffe coefficient of efficiency of about 0.71 for both models.

3. Calibrated parameter values were broadly correlated with the observed increase in runoff following the wild fire in 1990 with a reduced store capacity for AWBM and a reduced infiltration capacity for SimHyd.

4. The reduced stream flow occurred as a combined effect of a decrease in precipitation and an increase in potential evapotranspiration.

5. There is no significant correlation between peak hourly rainfall intensity and the error in modelled daily stream flow, implying that inclusion of information on rainfall intensity is unlikely to lead to an improved model performance.

6. Trend analysis indicates that the decrease in precipitation was most pronounced when daily amount exceeds about $10-20 \mathrm{~mm}$. This decrease in high-intensity precipitation may have accelerated the decrease in the observed stream flow from 1968 to 2006.

Acknowledgements. The author appreciates the assistance from Guillaume Thirel and his colleagues from IRSTEA in France for providing the hourly precipitation and stream flow data for the Rimbaud watershed, and for patiently addressing the numerous inquiries. In addition, the author wishes to thank the reviewers for their comments. 


\section{References}

Boughton, W. C.: An Australian water balance model for semiarid watershed, J. Soil Water Conserv., 10, 454-457, 1995.

Boughton, W. C.: The Australian water balance model, Environ. Modell. Softw., 19, 943-956, 2004.

Chiew, F. H. S., Peel, M. C., and Western, A. W.: Application and testing of the simple rainfall-runoff model SIMHYD, in: Mathematical Models of Small Watershed Hydrology and Applications, edited by: Singh, V. P. and Frevert, D. K., Water Resources: Littleton, Colo., 335-367, 2002.

Cosandey, C., Andréassian, V., Martin, C., Didon-Lescot, J. F., Lavabre, J., Folton, N., Mathys, N., and Richard, D.: The hydrological impact of the Mediterranean forest:a review of French research, J. Hydrol., 301, 235-249, 2005.

Kim, S., Vertessy, R. A., Perraud, J.-M., and Sung, Y.: Integration and application of the rainfall runoff library, Water Sci. Technol., 52, 275-282, 2005.

Nash, J. E. and Sutcliffe, J. V.: River flow forecasting through conceptual models. Part I - a discussion of principles, J. Hydrol., 10, 282-290, 1970.

Perraud, J.-M., Podger, G. M., Rahman, J. M., and Vertessy, R. A.: A new rainfall-runoff software library, Proc. MODSIM, 4, 17331738, 2003.
Podger, G. M.: Rainfall-Runoff Library user guide, available at: www.toolkit.net.au/rrl (last access: 20 March 2015), Cooperative Research Centre for Catchment Hydrology, 2003.

Ponce, V. M. and Hawkins, R. H.: Runoff curve number: has it reached maturity?, J. Hydrol. Eng. ASCE, 1, 11-19, 1996.

Porter, J. W. and McMahon, T. A.: Application of a catchment model in Southeastern Australia, J. Hydrol., 24, 121-134, 1975.

Thirel, G., Andréassian, V., Perrin, C., Audouy, J.-N., Berthet, L., Edwards, P. J., Folton, N., Furusho, C., Kuentz, A., Lerat, J., Lindström, G., Martin, E., Mathevet, T., Merz, R., Parajka, J., Ruelland, D., and Vaze, J.: An evaluation protocol to investigate how hydrological models deal with changing catchments, Hydrol. Sci. J., doi:10.1080/02626667.2014.967248, 2014.

Yu, B.: Adjustment of CLIGEN parameters to generate precipitation change scenarios in southeastern Australia, Catena, 61, 196-209, 2005.

Yu, B. and Zhu, Z.: A comparative assessment of AWBM and SimHyd for forested watersheds, Hydrol. Sci. J., doi:10.1080/02626667.2014.961924, 2014.

Zhang, Y. Q. and Chiew, F. H. S.: Relative merits of different methods for runoff predictions in ungauged catchments, Water Resour. Res., 45, W07412, doi:10.1029/2008wr007504, 2009. 